\title{
May You Live in Interesting Times. Science vs. Pseudoscience in the Era of the Internet
}

\section{Mariusz Szynkiewicz}

(Adam Mickiewicz University in Poznań; Poland; marszyn@amu.edu.pl)

ORCID: 0000-0001-8595-840X

... the problem of demarcation between science and pseudoscience

is not a pseudo-problem of armchair philosophers:

it has grave ethical and political implications.

(Lakatos 1980, 1)

\section{Science and Its Development}

May you live in interesting times, so the famous maxim goes. This phrase has often been referred to as a proverb, yet such reference is erroneous, since in fact it functions as a curse. What does it mean to live in interesting times? Undoubtedly, at least in the historical context, periods of political, social, scientific, or economic upheaval - or at least commotion, ferment, crisis - have certainly earned such a title. As have the epochs which were subject to radical transformations which distorted traditional relationships and institutions, existing patterns and rules. The above-mentioned "interestingness" is thus a function of a radical change, challenge and variability, somewhat a derivative of erosion, and of all that we associate with the notion of revolution or turn, be it political, social, economic, environmental, or scientific. The related trends described below are sometimes associated with challenges, and sometimes with victims of 'turns' and 'revolutions.' The paper's core aim is to examine the instant demarcation line between science and pseudoscience in the light of new trends such as misinformation, denialism, and the internetization and memoisation ${ }^{1}$ of scientific discourses.

Interesting times may concern science, both in its material and procedural dimensions, as well as its personal and institutional ones. Science is an ambiguous and multifaceted notion. The problem with its precise definition is due to its complexity and

1 This concept is derived from the term 'meme'; here it is employed to denote the phenomenon of transmitting information by means of simplified textual and graphic messages (mainly Internet memes). 
structure, and the wide spectrum of the impact of practical science. Science itself can be defined by its individual aspects. According to the typology proposed by philosophers, science is: a kind of knowledge (scientific knowledge); a kind of activity (research activity); methods of conducting a research process (scientific research methodologies); a certain type of community; institutions; social consciousness and a constituent part in society's productive potentials (Such 2004, 59).

Science can also be perceived as a diachronic object. In such a narrative our attention is drawn to its dynamic character. The variability of science is influenced by factors (determinants) which can be grouped as internal and external. The first group of determinants (e.g., compliance with empirical findings, the correspondence principle, the postulate of logical simplicity) is cognitive and usually has a positive effect on science. This means that science, which is largely dependent on internal determinants, can grow freely, constantly expanding the area of our knowledge, understood in descriptive and explanatory terms. The influence of its external determinants (the economy, technology, military needs, socio-political relations, social ideologies, intellectual climate and worldview) is more complex and ambiguous. They can both support scientific progress and inhibit it. Importantly, external factors that slow down the pace and even stop the conduct of certain studies are not always perceived negatively by society. An example of such a limitation imposed on scientific research activity, taken from the axiological sphere, is the limitation resulting from observing ethical codes that are applicable in various fields of science. In many cases, when the development of science is conditioned by the influence of external factors, this tendency assumes a negative dimension, with examples of ideological interventions in the development of $20^{\text {th }}$ century science (e.g., the influence of communist doctrine on the development of the Japhetic theory in linguistics (Robinson 2014, 194-254), Lysenkoism in biology (Joravsky 1970; Gordin 2012, 79-105) or the nationalist and socialist ideology program of the construction of the so-called Arische Physik (Ball 2916) and the reduction of theoretical mathematics in the Third Reich) (Piotrowska 2012).

The influence of external factors on the development of science has been recognized in numerous studies in the field of the social sciences and the humanities. In this context, not only were the aforementioned ideological pressures analyzed (Amsterdamski 1994; Feyerabend 1993; Joravsky 1970; Lakatos 1978; Merton1973), butalso pathological factors induced by a certain type of scientific policy (e.g., concerning the notorious evaluation of academic staff members (Goodstein 2017) or the existence of deeply rooted tendencies in society which are present in specific branches of science (Smolin 2006). When analyzing $21^{\text {st }}$ century science, one may indicate other crucial external determinants, expanding the list of threats discussed by the abovementioned authors in their works. In this article I will focus on one of them, which is an aftermath of the information revolution, related to the development of modern information technology. The problem is connected with the manner of creating, storing, distributing and acquiring knowledge on the internet. 
I will focus on three of selected and interrelated aspects of information culture in the internet era: information overload, and the phenomena of Information Smog and Post Truth. Referring to the problems mentioned above, I will try to describe the dangers resulting from the influence they have on the development of science and on societies participating in its achievements. Finally, I will focus on the perspective of change in the teaching philosophy resulting from a social transformation, which is a consequence of the process that can be defined as the internetization of knowledge in terms of remote and digital resources-based production and reproduction, publication and circulation, education and instruction. The background for the presented reflections will be one of the key and repeatedly analyzed problems in the philosophy of science - the issue of demarcation (Popper 2002; Pigliucci \& Boudry 2013) considered in terms of the relation between science and pseudoscience.

The presented analyses refer to the popularity of pseudoscientific information: a problem which I claim is one of the greatest challenges that scientists, methodologists, epistemologists and academic teachers are forced to deal with ${ }^{2}$. The growing dynamics of the spread of pseudoscience is one of the most dangerous consequences of the development of modern media (e.g., social media). This destructive process has become so powerful largely due to the structure and logic of the internet, and to the form of what we can call a cognitive culture ${ }^{3}$.

\section{Knowledge in Network Resources}

The origin and spread of internet technologies have led to fundamental changes in almost all areas of social activity. The internetization process was initiated at the cusp of the 1980s and 1990s through the commercialization of network technologies and the emergence and free release of World Wide Web technology by CERN. Radical changes also involved broadly understood information processes, which, in particular, concern the way scientific information is stored, transmitted and shared. The internet has gained the status of the most popular channel for exchanging and obtaining information. Apart from the phenomenon of network exclusion, one can even be as bold as to say that it has become a public source and also, increasingly, a free one. Already in 2015, the number of internet users was estimated at 3.2 billion (Davidson 2015), in July 2020, the number of users increased to 4,57 billion [Clement 2020]. Unfortunately, the development and

2 The scale of this problem becomes particularly important during extraordinary events, when scientific achievements are used directly to solve problems that have arisen. An example of such an event is the ongoing COVID-19 pandemic.

3 By cognitive culture I understand, after Bogdan Chwedeńczuk, the area of culture that is knowledge-oriented, consisting of the culture of notions, which "determines criteria and customs regulating the transparency of knowledge media, i.e., the borders of a cognitively promising discourse and the culture of tools encompassing: a toolbox to confirm and reject sentences, i.e., the conditions for determining, i.e., the borders of cognitively effective discourse" (Chwedeńczuk 2010). 
popularization of this new technology has also been accompanied by various negative consequences, such as the problem of information overload and the associated information smog - a phenomenon that is one of the factors contributing to the spread of pseudoscience ${ }^{4}$.

Information overload can be understood as a state resulting from the excess of available information, which, in the cognitive dimension, is directly related to the recipient of the information. It can take two forms: a) objective and quantitative - resulting from the disproportion between the cognitive abilities of a person and the amount of received informational stimuli; and b) subjective and qualitative, relating to the ability to assess the value of information (e.g., in the context of an individual's lack of cognitive competence, their lack of technical knowledge and ignorance of basic principles for assessing the epistemic value of obtained information ${ }^{5}$ ).

Information overload can be understood as a state resulting from the excess of available information, which, in the cognitive dimension, is directly related to the recipient of the information. It can take two forms: a) objective and quantitative - resulting from the disproportion between the cognitive abilities of a person and the amount of received informational stimuli; and b) subjective and qualitative, relating to the ability to assess the value of information (e.g., in the context of a lack of cognitive competence of an individual, lack of technical knowledge and ignorance of basic principles of assessing the epistemic value of obtained information). Information overload also has important practical implications for decision-making procedures. They result, among other things, from the difference between the amount of information available and the amount of information required to make decisions. Both the cognitive and the decision aspects illustrate the threats of the popularity and availability of pseudoscience. This phenomenon also allows us to understand the nature of problems related to information verification by nonscientists by explaining the tendency to use - as will be discussed later in subsequent sections simplified, biased and methodologically flawed information. In addition, it provides a basis for understanding the nature and origin of the information bubble phenomenon and the mechanism behind affirmative thinking - concepts I will discuss later in this text. Information overload, understood both as a specific state of the information environment and the disposition of the cognitive apparatus ${ }^{6}$, is linked to the notion of information smog, which can be analyzed from two main perspectives: qualitative (information credibility) and quantitative (excessive sources, content as well as fragmentation, and structure of information resources). Under information smog conditions, cognitive functioning is

4 An important issue currently under investigation is the use of 'bots' in disinformation campaigns. This problem is analysed, inter alia, in relation to knowledge from the medical sciences (Broniatowski \& Jamison 2018).

5 In the case of information producers, the following aspects are fundamental: substance (knowledge and skills of the author and the ability to assess the value of used resources), intention (the purpose for creating the message), scope of access to the resources, proper information production, processing, presenting and distribution skills.

6 Information overload can lead to so-called information shock (Babik 2014, 77; Golka 2008). 
unable to make effective use of available information resources. Information smog is also one of the factors contributing to the rise of threats related to the so-called post truth phenomenon. This concept emerged in the 1990s and was initially associated with politics. Subsequently, it entered the discourse on scientific issues ${ }^{7}$. This is not so much a phenomenon as it is a state of affairs in which tested, validated and reliable information has less power to influence and shape human attitudes than rhetorical arguments based on emotions and subjective beliefs. This state influences the discussion on scientific issues (e.g. medical, biological, ecological problems), facilitating the spread of pseudoscientific theories. Of course, the pseudoscience phenomenon itself is nothing new. In the last decades, however, the extent (scope of impact) and nature of information belonging to this area has changed. Due to the global nature of electronic media, pseudoscientific theories are gaining ground globally. Just like the so-called fake news which functions in political debates, pseudoscientific theories largely owe their popularity to the specificity of information functioning in the online environment. The power of this kind of cognitive phenomena can be analyzed both from the perspective of the producer and the consumer of information. In the past, the ability to create and propagate the results of cognitive activity was limited by the specificity of information channels, and, in the case of scientific information, also by the social structure of science itself. Information about scientific problems was transferred through a specific set of publications or various forms of speech. Publications usually were subject to critical review and speeches required the support of relevant authorities (e.g., qualifying speakers for the conference). The extent to which pseudo-information was influential was therefore limited. This model is of course still valid in scientific work. Nowadays, the production and consumption of information - also regarding science - is increasingly becoming available through open channels in which scientific and pseudo-scientific information compete to win the limited resources of the recipients' attention. The complexity of this situation is further aggravated by the fact that the traditional relationship between the knowledge producer and knowledge consumer is currently undergoing a substantial change under the internet conditions. The functions of the producer and the recipient of information often intermingle, e.g., on online forums or thematic blogs - taking the form of the so-called prosumer (Toffler 1985).

Searching for knowledge requires reference to personal sources - e.g., experts, teachers, researchers - as well as impersonal ones (textbooks, other books, articles). When traditional forms of communication dominated, the number of such sources was limited and the ability to assess their credibility (e.g., the expertise of a specialist due to his or her professional experience or academic status, or the scientific position of a journal or a publishing house) was relatively straightforward. At present, the search for information is often limited to network resources where scientific and pseudo-scientific

7 In 2016, the editors of the Oxford Dictionaries, on the basis of a research investigating the frequency of use of key words, granted the title of the word of the year to Post Truth (Flood 2016; The Guardian 2016). 
information operates - at least on a technical level - on a similar basis. This situation is further aggravated by the phenomenon of information smog. Excess information forces us to make quick and selective evaluations, and often it comes down to getting to know the contents of some of the most popular search records. The extreme example of this notion is the memoisation of knowledge. Unfortunately, the information available in search engines is not hierarchized according to scientific standards, but by the use of positioning mechanisms. Contemporary positioning algorithms, memorizing our earlier activity on the internet, are able to customize the content to suit individual user preferences, which is an additional - this time technological - incentive to create information bubbles ${ }^{8}$. Similar phenomena are furtherly reinforced by the psychological tendency to search for confirmations, which may result in confirmationism, a self-confirmation bias manifesting itself as a preference for information confirming the subjective views and opinions of the recipient, while one tends to avoid information which could disconfirm or put in question one's own opinions and views, and examine (and finally even strengthen) their epistemological validity.

\section{Social Engineering in the Service of Pseudoscience}

The impact of factors resulting from technological changes and psychological predispositions on the popularity of pseudoscience is one of the most interesting issues related to the development of the internet. No less interesting is the analysis of techniques used by the creators and supporters of pseudoscientific concepts in the propagation of their views. Scientific results have an objective, empirical, methodological and logical applicable advantage over pseudoscientific information (Nowak, Abriszewski \& Wróblewski 2016). Without having similar qualities, pseudoscience can reach for manipulative tools which are widespread in the field of advertising and political marketing.

In 1937, a list of the most widely used propaganda techniques was developed at the Columbia University Institute for Propaganda Analysis. This list included such tools for image creation as: name calling to discredit particular people, concepts or products; glittering generality to hide or blur the real intentions of authors by referring to positive values; plain folks, that is referring to ordinary people, average citizens, standard patients etc.; transfer - references to persons (known actors, moral authorities) or groups (e.g., doctors, scientists) who command a particular social respect ,or the use of opinions and quotes outside their actual context; testimonial - the proclamation of allegedly obvious and irrefutable opinions; and the bandwagon effect, that is referring to the universality of

8 The phenomenon of the information bubble can take several fundamental forms. In the context of problems discussed in this article, I shall mention two of them. The first one refers to the decisionmaking process and consists in the more or less conscious selection of information confirming our point of view and rejecting information which is contradictory. The other is of a technological character and is related to the functioning of search engines, which, on the basis of the activity of internet users, position the presented content. 
a given statement, opinion or hypothesis; as well as 'card stacking', the mixing of true and false, logical and illogical arguments, biased selection of information, misuse of statistics, and arbitrary interpretation of data to comply with a predetermined assumption (Sproule 1997, 135).

Through analyzing the methods of the popularization of both contemporary and historical pseudoscientific theories, the widespread tendency to exploit propaganda tricks becomes overt. Referring to the aforementioned catalog of sociotechnical tools, we see that the most commonly applied ones include the use of the so-called epithets. As examples, we can mention those applied by Lysenko in his struggle against Mendelian-Morganian genetics (Stanchevici 2017), the ideological criticism of the uncertainty principle (Graham 1991), or accusing persons fighting against pseudoscientific information of participating in various conspiracy organizations. Nowadays, these arguments are popular, e.g., among by the supporters of the chemtrails theory or various forms of denialism (Hanson 2017).

Another common sociotechnical trick is the reliance on authority. Interestingly, in many cases propagators of pseudoscience, attacking recognized scientific achievements, the scientific community and scientific institutions [Knobel 2020] or even science itself as a form of cognition (mainly in methodological terms), do not hesitate to refer to the authority of this very science (sic!). In this way they try to prove that their views are based on reliable and objective grounds ${ }^{9}$. As an example, we can cite the research findings of Andrew Wakefield ${ }^{10}$, to which the supporters of the anti-vaccination movement refer. The opinion of an authority often takes a personal form. Interestingly, proponents of antiscientific theories refer to both existing and fictional authorities (Wróblewski 1987, 163). In this first case, they often present illegitimate interpretations of research results or refer to the opinions of people who are not professionals in the field which the analysis concerns.

Another popular propaganda tool used to promote pseudoscience is a technique called card stacking. Most pseudoscientific concepts are a collection of true and false arguments, biased in their interpretation, or they may be a direct consequence of overinterpreting the obtained results ${ }^{11}$.

A common feature of pseudoscientific theories is a specific form of denialism, which,

9 Another paradox is the fact that modern pseudoscience is developing mainly due to technologies based on the achievements of this very criticized science.

10 The article by Wakefield was published in 1998 in the prestigious Lancet journal and, subsequently, due to a conducted investigation - was deemed scientifically unreliable. This aspect of Wakefield's research is usually omitted by the opponents of vaccination or interpreted as evidence of an existing conspiracy involving both scientists and the pharmaceutical industry. The resistance to vaccination had already emerged in the 18th century. At present, the antivaccination movement refers to the results of research conducted by G. Stewart and by M. and D. Geier concerning the supposed link between tiomersal (a preservative) and autism, which have been judged unreliable (Marchewka, Majewska, \& Młynarczyk 2015, 95-97).

$11 \mathrm{~A}$. Kata conducted an analysis of techniques applied by the opponents of vaccination in internet publications. The tools indicated by her (e.g., criticizing their opponents, over-interpretation of research results, referring to emotions) correlate with the abovementioned techniques of manipulation (Kata 2010, 1709-1716; Kata 2012, 3778-3789). 
however, is not to be confused with criticism, an extremely important attitude in the case of science ${ }^{12}$. Pseudoscience also has a typically confirmatory character. Its supporters seek, above all, evidence to support the preconceived assumptions, disparaging or discrediting the negative results and interpretations. Proponents of pseudoscientific explanations reject the hypothetical model of science, and in many cases are even inclined to assume the existence of final explanations. Pseudoscientists do not seem to understand the logic of scientific cognition, exploiting the hypothetical nature of scientific laws and theories as an argument against the legitimacy of criticized explanations (Bunge 1984).

As a cognitive and social phenomenon, pseudoscience can be identified not only at the methodological, logical or empirical levels, but also in the semantic dimension. The mere analysis of the language which is used to create messages classified in this category allows some of their characteristic features to be captured. The dry, objective scientific language lacking epithets is replaced by structures that refer to emotions (e.g., some examples in the field of alternative medicine), religion (e.g., some types of creationist doctrine), or are ideologically or politically marked (e.g., Arische Physik, creative Soviet Darwinism, Japhetic Theory, Young Earth creationism). A common practice of pseudoscientists is also the use of titles and leads in the presented publications which contain unequivocal theses and evaluations. Other features of pseudoscience include the abuse of professional language - usually outside the context or even in a way that is devoid of scientific meaning, references to individual and unconfirmed experimental research results, source deficiencies (e.g. common tendency to quote figures without indicating sources), referring to texts without any scientific value accessed from unreliable sources and the use of unauthorized and misleading simplifications and oversimplifications.

Pseudoscience is not merely a seemingly innocuous extravagance or an insignificant competitor of cognitive and applicable scientific knowledge. Due to its popularity, it is becoming a serious threat to the proper functioning of modern societies (e.g., the consequences of the anti-vaccination movement's activity $)^{13}$. While the propositions of the proponents of flat Earth theory or E. von Däniken's theory can be considered insignificant, the social consequences of the activity of the anti-vaccination movement or of some forms of alternative therapies can have measurable and overtly negative consequences (Boseley 2018). This phenomenon is most easily illustrated by examples in the field of medicine. In such cases, the consequences of applying the recommendations of pseudoscientists can be both individual and social. In the former case, they relate to the health of an individual patient and are a consequence of rejecting recognized and validated medical forms of

12 Diethelm and McKee classified the following characteristic attitudes: referring to false authorities, formal errors and logical misuses, constant demand for new evidence, selectivity (of arguments), conspiracy thinking (Diethelm \& McKee 2009, 2-4).

13 This problem became particularly evident in the face of the COVID-19 pandemic. The spread of SARS-CoV-2 has been accompanied by numerous negative phenomena associated with the promotion of false information in the public domain concerning various aspects of the pandemic. This phenomenon is currently also being investigated in communication contexts (Gallotti et al. 2020). 
treatment or pharmaceuticals for untested or therapeutically unprofessional means. In the trans-individual dimension, the consequences can also have a social dimension, and a good example of this is the so-called herd immunity in the case of protective vaccination practice (Gordis 2014, 26-27).

The grooving popularity of pseudoscientific theories ${ }^{14}$ can further jeopardize the development of science defined as a type of rational knowledge and of cognitive activity. In societies where pseudoscience proposals are gaining popularity, one may observe the emergence of political elites professing similar views and restricting subsidies for scientific research in favor of the so-called alternative methods, which was particularly overt in the case of the support the national authorities granted to the concept of Lysenkoism and the administrative struggle with traditional genetics in the USSR.

\section{Conclusions}

The distinctive characteristic of the information environment of our time is undoubtedly information overload. We can even take the risk of claiming that we indeed are dealing now with a certain inflation of information. The main problem of the information environment is currently not the shortage of available information, but its excess and lack of proper structure. As W. Babik emphasizes, "in contrast to the past, when people could have had the impression that they suffer from the lack of information, at present, the amount of available information outstrips the possibilities of human perception" (Babik $2014,76)$. This state also concerns the practice of teaching. Traditional teaching methods were adapted to the situation in which information was deficient and difficult to access, and so the learning process was based on the ability to acquire and memorize. Under the conditions of information surfeit, the accumulation of knowledge seems to be pushed to the margins. Information is now a commodity which is readily available, cheap, and, thanks to the use of the internet, almost ubiquitous. The real challenge which the information society has to face is the need to develop and implement, already at the level of elementary education, the ability to evaluate, select and use information (Knobel 2020). The first two of these abilities also apply to information sources. The problem of searching - typical for the deficit phase - transforms into the problem of choice, characteristic of the state of surfeit and overproduction. The consequences of the overproduction of information are the phenomena of information smog and information stress. This state necessitates a change in the teaching model. The first aspect of the new didactic perspective is directive in character. Its consequence should be more emphasis placed on the valorization

14 The research carried out by a team of scientists from MIT showed that false information spread much more effectively in the communication space of the Internet than scientifically confirmed content (e.g. from reviewed sources), both in temporal terms (the time it takes for information to disseminate) and spatial terms (the area covered and the number of recipients). Observations concerning the scale of the dissemination of false information on social networking sites are of particular interest (Vosoughi et al. 2018). 
and selection of informative content, both in terms of technology (use of appropriate search tools) as well as didactics (e.g., the importance and position of expert networks) (Fazgalić 2007) or equipping a student with the ability to distinguish valuable pieces of information from redundant and worthless ones ${ }^{15}$ ). The latter is related to normative issues and the necessity of establishing a cognitive culture, emphasizing the advantage of scientific explanations over pseudoscientific concepts. A crucial element of this process is the awareness of the need to evaluate information, the importance of cognitive criticism and the responsibility for information (mainly in the context of its practical and social consequences). In our reflection on science we should very clearly take into account alongside classic epistemological, methodological, logical or sociological issues - also aspects which concern the ecology of information (Babik 2014).

In conclusion, we can say that the change in teaching methods should be based on several essential elements. Firstly, the ability to recognize different fields of knowledge, and thus differentiate between the cognitive value of knowledge and fake news, post truths, or other messages simulating the products of science. Secondly, the identification of dangers associated with the acceptance of pseudoscientific explanations, and with the extreme memoisation of knowledge including simplification, deformation, reductionism, etc. Thirdly, the ability to identify methods and techniques of manipulation in the scientific discourse (e.g., the propaganda tools described above), which are used by the promoters of pseudoscientific concepts ${ }^{16}$.

This transformation must also take into account the attitude of the teachers and the creators of knowledge themselves. This is primarily about the awareness of the responsibility of scientists and teachers for knowledge in its three essential aspects: content, methodology and didactics. The last of the mentioned elements highlights the importance of popularizing the achievements of science -this process is often understated among academics, and is usually used only as an element of promoting the educational offer of individual universities. If society is to decide about education, for example due to the fact that it is expensive, we must value the popularization of knowledge among those who, by political decisions, directly or indirectly influence the shaping of the state's policy concerning science. Such activities concern the whole of society. The effectiveness in promoting scientific knowledge and knowledge of science (its character, meaning, possibilities and limitations) should be greater than the influencing power of those who, exploiting the opportunities resulting from the surfeit of information and the possibilities of modern communication, have perfected the techniques of propagating their ignorance.

15 Such programs are currently being implemented in Swedish schools (Roden 2017).

16 As a result of the outbreak of pseudo-scientific practices, the role of teachers changes as well. As Fazlagić points out: they transform from information suppliers to the managers of the learning process. The application of the achievements of neuroscience can further support modern education (wider discussed in Fazlagić 2010). 


\section{References}

Ajdukiewicz K. 1957. „O wolności nauki,” Nauka Polska 3.

Amsterdamski S. 1994. Tertium non datur? Szkice i polemiki. Warszawa: Wydawnictwo PWN.

Babik W. 2014. Ekologia informacji. Kraków: Wydawnictwo Uniwersytetu Jagiellońskiego.

Ball P. 2016. Science and Ideology: The Case of Physics in Nazi Germany, https://ojs.uv.es/ index.php/Metode/article/view/7665/9758 (last accessed August 22, 2019).

Boseley S. 2018. "Measles Cases at Highest for 20 Years in Europe, As Anti-vaccine Movement Grows," The Guardian, December 21, 2018, https://www.theguardian. com/world/2018/dec/21/measles-cases-at-highest-for-20-years-in-europe-asanti-vaccine-movement-grows (last accessed on August 24, 2020).

Broniatowski D., Jamison A., Qui S., Alkulaib L., Chen T., Benton A., Quinn S., \& Dredze M. 2018. "Weaponized Health Communication: Twitter Bots and Russian Trolls Amplify the Vaccine Debate," American Journal of Public Health 108(10):13781384. DOI: 10.2105/AJPH.2018.304567 (last accessed on August 24, 2020).

Bunge M. 1984. “What Is Pseudoscience?," The Skeptical Inquirer 9(1):36-46.

Chwedeńczuk B. 2010. „Czy istnieją pytania filozoficzne?” http://www.racjonalista.pl/ pdf.php/s,7339, p. 3 (last accessed on August 24, 2020).

Clement J. 2020. "Worldwide Digital Population as of July 2020", Statista, https://www. statista.com/statistics/617136/digital-population-worldwide/ (last accessed on August 24, 2020].

Davidson J. 2015. “Here's How Many Internet Users There Are”, Time Magazine, http:// time.com/money/3896219/internet-users-worldwide/ (last accessed on May 18, 2017).

Diethelm P. \& McKee M. 2009. "Denialism: What Is It and How Should Scientists Respond?" European Journal of Public Health” 19(1):2-4.

Feyerabend P. 1993. Against Method. London - New York: Verso.

Fazlagić J. A. 2010. „Zjawisko 'nadmiaru informacji' a współczesna edukacja,” http:// www.e-mentor.edu.pl/artykul/index/numer/36/id/773 (last accessed on May 18, 2020).

Flood A. 2016. 'Post-truth' Named Word of the Year by Oxford Dictionaries," The Guardian, https://www.theguardian.com/books/2016/nov/15/post-truthnamed-word-of-the-year-by-oxford-dictionaries (last accessed 18.05. 2020).

Gallotti R., Valle F., Castaldo N., Sacco P., \& DeDomenico M. 2020. "Assessing the Risks of «Infodemics» in Response to COVID-19 Epidemics," medRxiv (preprint). URL: https://www.medrxiv.org/content/10.1101/2020.04.08.20057968v1.full.pdf (last accessed on August 24, 2020). 
Golka M. 2008. Bariery w komunikowaniu i społeczeństwo (dez)informacyjne. Warszawa: PWN.

Goodstein D. 2002. "Conduct and Misconduct in Science," in P. R. Gross, N. Levitt, \& M. W. Lewis (Eds.), The Flight From Science and Reason (pp. 775-831). New York: The New York Academy of Sciences, http://www.its.caltech.edu/ dg/conduct_art. html (last accessed on April 17, 2020).

Gordin M. D. 2012. The Pseudoscience Wars: Immanuel Velikovsky and the Birth of the Modern Fringe (pp. 79-105). Chicago: University Of Chicago Press.

Gordis L. 2014. Epidemiology. New York: Elsevier-Sounders.

Hoffman B. L., Felter E. M., Chu K. H., Shensa A., Hermann Ch., Wolynn T., Williams D., \& Primack B. A. 2019. "It's Not All about Autism: The Emerging Landscape of Antivaccination Sentiment on Facebook," Vaccine 37(16):2216-2223.

Joravsky D. 1970. The Lysenko Affair. Chicago: University of Chicago Press.

Kata A. 2010. "A Postmodern Pandora's Box: Anti-vaccination Misinformation on the Internet," Vaccine 28:1709-1716.

Kata A. 2012. "Anti-vaccine Activists, Web 2.0, and the Postmodern Paradigm - An Overview of Tactics and Tropes Used Online by the Anti-vaccination Movement," Vaccine 30:3778-3789.

Knobel M. 2020. "The Role of Communication in a Post-truth World," University World News from 08.02.2020, https://www.universityworldnews.com/post. php?story=20200203141227255 (last accessed on August 24, 2020).

Lakatos I. 1978. “The Methodology of Scientific Research Programmes," in J. Worrall \& G. Currie (Eds.), Philosophical Papers, vol. 1, Cambridge University Press.

Roden L. 2017. "Swedish Kids to Learn Computer Coding and How To Spot Fake News in Primary School," https://www.thelocal.se/20170313/swedish-kids-to-learncomputer-coding-and-how-to-spot-fake-news-in-primary-school llast accessed on August 24, 2020).

Smolin L. 2006. The Trouble with Physics: The Rise of String Theory, the Fall of a Science, and What Comes Next. Boston: Houghton Mifflin.

Marchewka A. K., Majewska A., \& Młynarczyk G. 2015. „Działalność ruchu antyszczepionkowego, rola środków masowego komunikowania oraz wpływ poglądów religijnych na postawę wobec szczepień ochronnych," Postępy Mikrobiologii 52(2):95-97.

Merton R. K. 1973. The Sociology of Science: Theoretical and Empirical Investigations. Chicago: University of Chicago Press.

Nowak A. W., Abriszewski K., \& Wróblewski M. 2016. Czyje lęki? Czyja nauka? Struktury wiedzy wobec kontrowersji naukowo-społecznych. Poznań: Wydawnictwo Naukowe UAM.

Pigliucci M. \& Boudry M. (Eds.) 2013. Philosophy of Pseudoscience: Reconsidering the Demarcation Problem. Chicago: University of Chicago Press. 
Piotrowska E. 2012. Nauka a ideologia. Matematycy i matematyka w III Rzeszy. Poznań: UAM Poznań Editions.

Popper K. R. 2002. The Logic of Scientific Discovery. London - New York: Routledge.

Robinson M. 2014. Losy elity akademickiej. Rosyjska slawistyka od 1917 roku do początku lat 30, trans. M. Skarżyński. Warszawa: Wydawnictwo Akademickie Sedno.

Smolin L. 2006. The Trouble with Physics: The Rise of String Theory, the Fall of a Science, and What Comes Next. Boston: Houghton Mifflin.

Sproule J. M. 1997. Propaganda and Democracy: The American Experience of Media and Mass Persuasion. Cambridge: Cambridge University Press.

Such J. 2004. Multiformity of Science. Amsterdam - New York: Rodopi.

Such J. 2009. „Racjonalność przyrody a racjonalność życia społecznego,” in Z.

Drozdowicz, Z. Melosik, \& S. Sztajer (Eds.), O racjonalności w nauce i życiu społecznym. Poznań: Wydawnictwo Naukowe WNS UAM.

Vosough S., Roya D., \& Arala S. 2018 (March 09). "The Spread of True and False News Online," Science 359(6380):1146-1151. DOI: 10.1126/science.aap9559

Wróblewski A. K. 1987. Prawda i mity w nauce. Warszawa: Iskry. 


\title{
Mariusz Szynkiewicz (Poznań) \\ May You Live in Interesting Times. \\ Science vs. Pseudoscience in the Era of the Internet
}

\begin{abstract}
May you live in interesting times, the famous maxim quotes. Undoubtedly, at least in the historical context, periods of political, social, scientific, or economic riots - or at least commotion, ferment, crisis - have certainly earned such a title. So have the epochs which were subject to radical transformations distorting traditional relationships and institutions, existing patterns and rules. The abovementioned "interestingness" is thus a function of a radical change, challenge and variability, somewhat a derivative of erosion, and of all that we associate it with the notion of revolution or turn, be it political, social, economic, environmental, or scientific. The paper's core aim is to examine the nowadays constantly revised, questioned, thus, shaking demarcation between science and pseudoscience in the light of new trends such as misinformation, denialism, internetisation and memoisation of scientific discourses.
\end{abstract}

Keywords: science; pseudoscience; social responsibility; internet and internetisation; misinformation, memoisation; denialism; data smog.

Ethics in Progress (ISSN 2084-9257). Vol. 11 (2020). No. 1, Art. \#5, pp. 85-98.

Creative Commons BY-SA 4.0

DOI:10.14746/eip.2020.1.5 